\title{
Course Delivery Platform Changes and Instructional Delivery Methods: Student Attitudes and Perceptions
}

\author{
William E. Garner ${ }^{1, *}$, Tresvil G. Pack ${ }^{2}$, Gary M. Szirony ${ }^{3}$, Eric T. Beeson ${ }^{4}$ \\ ${ }^{1}$ University of Arkansas at Little Rock, Little Rock, AR 72211, United States \\ ${ }^{2}$ Capella University, Conway, AR 72032, United States \\ ${ }^{3}$ Walden University, Athens, Ohio 45701, United States \\ ${ }^{4}$ Ohio University, Athens, Ohio 45701, United States \\ *Corresponding Author: wegarner@ualr.edu
}

Copyright (C) 2013 Horizon Research Publishing All rights reserved.

\begin{abstract}
The purposes of this study were to examine students' perceptions and attitudes toward changes in Distance Education (DE) course management systems and to evaluate their instructional delivery preferences. Students (N $=145$ ) enrolled in an online master's degree program on either a full- or part-time basis completed an online survey instrument specifically designed for this study. Results showed a strong preference for distance education, but no significant differences in student perceptions toward changes in Course Management Systems (CMS). The benefit of transparency in course design is discussed along with other findings.
\end{abstract}

Keywords Distance Education, Web Course Design, Counseling, Course Management Systems, Course Management Administration

\section{Introduction}

Distance education is a growing area of research and perceptions of students and faculty represent important administrative concerns. Distance learning is defined “.... as a course in which the expectation is that the student and instructor will not be physically copresent in the same location"(p.404) [1]. These authors further note that Distance Education (DE) “.... is not a one-dimensional construct [and thus] refers to a wide range of pedagogical choices and instructional tools" (p. 404). In addition, Maguire[2], in a review of the attitudes of higher education faculty toward teaching using this medium, noted, "...most definitions specify that distance education is teaching and learning that occurs asynchronously" (p. 2). Thus, these new technologies and instructional methods, in whatever form and shape they may take, are not designed to change the goals of education but rather "...change the process of communication within an educational setting to accomplish those goals" (p. 403) [1]. Distance education may be of considerable benefit based upon several considerations, including ecological factors. In order to deliver online coursework, organizations often rely upon some form of course management software that is often referred to as a "platform" or a Course Management System (CMS).

Instructional formats may also include a variety of hardware and software combinations designed to accomplish the instructional goals of faculty members as well as meeting the needs of the target audience, in this case, students or learners [3]. Regardless of the format and specific technologies involved, Forster and Washington[4] believe that despite the various controversies which exist as to whether DE or on-campus is the preferred mode of instruction, "...consideration will likely shift increasingly from whether to use distance education to how it can be delivered in the most effective and efficient manner (emphasis added)" (p. 147).

A review of the research literature regarding online education is instructive. Two general areas of research have emerged: 1) student perceptions of $\mathrm{DE}$ and 2) program issues involved in this alternative form of education. According to Lorenzetti[5], student and enrollment trends make DE more necessary than before, and the importance of flexibility in the student schedule and other life circumstances warrant this review and continuing research in DE.

\subsection{Student Perceptions of DE}

In a study of specific academic programs using online learning tools, Andrew[3] provided a thorough descriptive study of DE across a subsection of Rehabilitation Master's Degree programs $(\mathrm{N}=25)$ in the United States. Andrew's results indicated that most $(60 \%)$ of the students enrolled in these programs were currently on a full or part time basis. A number of positive perceptions of DE by students were observed. An increase in student satisfaction has been correlated with the unique opportunities of DE. Increased flexibility, freedom of schedule, and pacing their course work have been identified as variables of DE that aid in 
student satisfaction [5-7]. Rad [7] attributed the phenomenal growth of $\mathrm{DE}$ in the past decade to its unique ability to allow students to maintain travel and work obligations. Since that research, DE continues to experience high growth rates. Furthermore, $\operatorname{Rad}[7]$ noted that $\mathrm{DE}$ "...extends the boundaries of the campus to a global dimension" (p. 2). Additional positive perceptions included being able to work while attending school, having access to education while living in a rural area, being able to pace themselves throughout their coursework, and eliminating travel barriers associated with disabilities [7].

McLean and Murrell[8] found students to be overwhelmingly satisfied with the development and sophistication of their computer skills resulting from the technical nature of a computer-based course management system. This study looked at the implementation of a web-based curriculum into a traditional medical curriculum. They found that students " ...enthusiastically accepted its integration into a new curriculum" (p. 13), quickly adapted to the computer-based environment, and successfully adapted to the self-directed learning involved in this new curricular addition [8]. The vast majority of students surveyed for their perceptions regarding this CMS indicated that they found it added value to their learning modules. Fully $83 \%$ of students surveyed found the ability to save information to computer disks, USB flash drives, or other forms of backup to be constructive. Bequiri, Chase, and Bishka[9] suggested a student profile to describe students most satisfied with online coursework including graduate, married, residing off campus, and male. In addition, these authors suggested having some familiarity with the content of the course would enhance the student's satisfaction with online course delivery.

Despite the positive perceptions mentioned above, a number of negative perceptions have also been noted. DE courses have been perceived by some to require a large amount of time [7,8]. Additional student frustrations included technical problems and the lack of face-to-face contact with faculty and other students. Although some have found students to acclimate rather easily to the self-directed online environment [8], additional concern has also been raised given the necessity of students' self-motivation and reduced social and emotional contact [7]. Distance education courses often have a technology fee, which makes some online courses more expensive, thus discouraging students from lower socio-economic demographic groups [6].

\subsection{Program Issues with DE}

Program issues with DE have warranted additional focus from researchers. In Andrew's[3] study, two-thirds of the 25 programs surveyed, as mentioned above, viewed their on-campus courses and DE courses to be "...virtually identical..." (p. 19) despite some variability in class sizes that existed across programs. In addition, most programs used open enrollment such that students could begin their program during any given semester, although some programs (less than 1/3) used a cadre system where students would progress through the program as a cohort.

Two predominant CMS have been identified throughout the literature. Given the purpose of this article, anonymity for the specific CMS is maintained and will be referred to as CMS A and CMS B. The two predominant CMS used by students responding from the 25 programs in the study indicated that CMS B and CMS A dominated the list of software used at that time to deliver DE courses [3]. Supported in the research of Falvo and Johnson[10], they found CMS B (33\%) and CMS A (18\%) to be the most commonly used platforms in online course delivery prior to the acquisition of CMS A by CMS B. There is no indication in Andrew's[3] study, however, that any program used multiple software programs simultaneously to deliver DE courses. Surprisingly, most programs $(80 \%)$ considered the development of DE courses as part of the normal workload for faculty members teaching those courses. In addition, most programs $(\mathrm{N}=22)$ provided technological specialists in an effort to support students.

Given daily technological advances and the market growth for CMS, platforms are being updated and changed regularly causing a number of program issues related to the transition to new or updated CMS platforms. One Mid-Western university attempted to merge nine different CMS to one uniform CMS that would serve all schools in the university efficiently and cost-effectively [11]. In addition, some faculty members reported that as much as $30 \%$ of students would be opposed to the change in CMS. Problems during the merger affected both course delivery and faculty/student satisfaction. For example, some course content did not transfer over and thus was not converted as "...intact [content was unchanged]..." or "... accurate [precise and free from error]..." (p. 69). Therefore, additional research is warranted to address concerns in the administration and faculty perceptions of $\mathrm{DE}$ in an ever-changing education environment.

This literature review identified both satisfaction and dissatisfaction issues related to the use of DE on both the part of students and faculty perceptions. The extent of these perceptions may be important to the acceptance and success of DE by both faculty members and students. Based upon the results identified in Smart and Meyer[11], the purpose of this study was to examine the perceptions, characteristics, and attitudes of student learners enrolled in an online rehabilitation counseling graduate program hosted at a university in the Mid-South that was experiencing a change in DE platforms.

This change created-a-unique population groups 1) students who had only taken courses in CMS B, 2) students who had only taken courses in CMS A, and 3) students who had taken courses in both CMS B and CMS A. The perceptions of these subgroups of students during the transition will expand upon the current literature and provide direction to administrators of DE programs going through similar platform transitions. The research questions were as follows: 
1). Are there significant differences among student groups between preferences for the CMS B or CMS A course management systems?

2). Are there significant differences among student groups regarding their perceptions of their computer proficiency for the CMS B and CMS A course management systems?

3). Are there significant differences between group members' specific demographic characteristics and perceptions of computer proficiency for the CMS B and CMS A course management systems?

4). Are there significant correlations among the entire student sample regarding their characteristics, perceptions, and attitudes toward distance education?

5). Are there any significant differences between additional demographic variables?

\section{Methods}

\subsection{Program Description}

Research for this study was centered on a program that was designed to provide an open learning environment for all students. One of the goals of the program was to provide course content and skill training similar to that which would be delivered in an on campus venue [12]. The distinguishing feature of the on-line format was the accommodation strategy had evolved, making the online courses accessible for persons with a wide variety of disabilities and learning preferences. Not only did this appeal to learners who had a preference for visual, text based or video based learning, but it made it possible for students with visual and hearing impairments to access course material. This design aspect was a key feature of the program used in this study, moving closer to a universal design concept. This concept further supports the use of DE programs to eliminate barriers to education noted by $\operatorname{Rad}[7]$.

The online program methodology used streaming video (videostreaming) technology, Chromakey equipment (sometimes referred to as "green screen" technology), text and PowerPoint presentations to deliver lecture materials online in an asynchronous videostreamed format. With this approach, the online content and experience may be compared favorably to what a student might encounter in attending an on-campus class.

\subsection{Participants}

The program studied in this investigation had over 300 students enrolled from 48 states, the District of Columbia, \& seven other countries. Thirty-three percent of the students enrolled each semester were minorities and 35\% were students with disabilities. Most of the students enrolled in the program $(80 \%)$ were employed on a full-time basis. Most students took classes on a part-time basis. The modal number of graduate classes taken by students per semester was two.

Graduate students $(\mathrm{N}=145)$ were sampled through an email database that was maintained within the program. Email recipients were combined into several batches. Participants were selected from the existing database that contained both past and current students who had taken or were taking classes, beginning in the year 2000 at the onset of the program. When participants were listed as having more than one email address on file, only one was selected from the list. Thus, participants with multiple email addresses only completed the survey once.

\subsection{Design}

This study used a mixed-method design, although this article focused upon the quantitative aspects of the survey. As will be noted in the Instrumentation section, the survey designed by the research team and used in this study contained both quantitative and qualitative items. A research strategy such as a mixed-method design, which integrates different methods within the same study, is likely to produce better results in terms of quality and scope of information produced [13]. The qualitative aspects of the survey were addressed in a separate article. This article aimed to report the quantitative results of the study.

\subsection{Procedures}

Once Internal Review Board (IRB) approval was received and participant selection was completed, students were notified via email of the opportunity to participate in an online survey. An email message was composed asking past and present students to complete a survey designed to help in the development and continued improvement of the program. The message informed each participant of the confidentiality of their information and the importance of their feedback. An approximate time it would take to complete the survey (about five minutes) was also contained in the email message. Within the email message, a direct link taking the participant to the main survey page was included, minimizing the effort required to take the survey.

The email message was sent to the list of participants three times following monthly reminders from faculty in all classes taught online during the semester. Thus, students were reminded, at least once per month per class offered during that semester, of the opportunity to participate in the survey. Students were encouraged to participate, but under no circumstances were they ever coerced. No contingency rewards were offered for their participation, although faculty reminders and the accompanying online cover letter which preceded access to the actual survey expressed appreciation for their participation and suggested that their participation would be both anonymous and beneficial for curricular and program development and planning.

\subsection{Instrumentation}

Collection of data was completed with the use of a mixed-method evaluation design [13] using a web-based 
survey. The survey was designed, written in html, and published specifically for this study by members of the research team. Every intention during design, development, and implementation was to keep the survey as brief and easy to complete as possible. Attention was paid to response time and minimizing the navigation and need for "drilling down" through too many layers of web pages. Participants reached the initial survey questions after only two clicks. Responsiveness, reliability, confidentiality and ease of use guided the development of this survey. Once written and tested thoroughly, including several preliminary test runs by the research team, the survey was then hosted on a fast, reliable and secure server capable of collecting data efficiently, safely and confidentially.

Upon reaching the online Survey title page, each participant was able to review the human subject information, including a statement concerning anonymity and confidentiality. No information specific to either the identity of any participant or any IP address of a sending computer was collected or saved. After reviewing the confidentiality agreement, the participant then chose to click on either of two links: "Accept" or "Decline." The "Accept" link took the participant to the first of five contiguous survey pages making up the five sections of the survey.

Section one. The first section of the survey, titled "Web Based Learning," consisted of 15 Likert-type questions, each with five possible responses ranging from "Strongly Agree" (1) to "Strongly Disagree (5)." The first section was designed to gather information regarding general experience in distance education and comfort level of each participant in computer use. For example, the first two questions read, "I am comfortable working with computers," and "I have had previous experience in distance learning courses." Cronbach's alpha for this scale was calculated at $\alpha=.86$ [14], which was believed to be an acceptable level of internal consistency for this type of measure and for the intended purposes of this study.

Section two. The second section of the online survey was designed to gather college degree seeking information, including whether or not the participant was currently enrolled in a Masters level program, the year of completion of their bachelor's degree, current work setting (from a drop down box listing several choices) and general interest in future pursuits of a doctorate degree.

Section three. The third section of the online survey was a very short section intended to acquire general demographic information from each participant. Age, race, gender, disability, and location (state and nation choices from a convenient drop down box) were included given the diversity of the participants. Three additional questions specific to the pursuit of certification and licensure in the field of interest were also presented in this section.

Section four. The fourth section of the online survey, titled, "Technical Information," was designed to gather specific data regarding computer type ( $\mathrm{PC}$ or Mac), operating system (from a drop down box of choices including Mac OS X, XP Pro, XP Home, Windows 2000,
Windows 98, Unix/Linux, Vista, etc.), Internet browser used, primarily Microsoft Internet Explorer, Mozilla Firefox, or Safari (for Mac), also from a drop down box, and some additional information regarding the number of CMS used for distance education in the past. A question specific to where the participant did most or their work (i.e., work or home) was also included. A checkbox list of computer functions such as email, chat rooms, Phone Bridge, video or text-based learning was included. Users were asked to check any and all in which they had experience. The intention was to gain an understanding of level of expertise along with isolating technical information. A possible comparison between these levels of experience, technical characteristics of hardware, software and connectivity, and comfort level of the user was the original intent.

Section five. The fifth and last section, entitled, "Comments," provided a mechanism to gather qualitative data concerning what participants liked or disliked about videostreamed distance learning, about CMS A and about the CMS B course management systems. A "General Comments" text box concluded the survey, giving the participant the opportunity to enter any information they chose about distance education or about the survey itself. Upon completion, the participant clicked a "Submit" key that sent the data to a database on the secure server. Having no IP address or identifying information specific to the participant, the coded data form was then sent to the researcher's private email address within the same host server via an internal $\mathrm{html}$ command. Data was then verified for completion, checked to prevent any duplicate data, and a backup copy placed in a secure and locked location.

\subsection{Data Analysis Procedures}

The data for the quantitative side of this mixed-method evaluation design [13] to determine any group differences across several variables, to the extent that they existed, were examined through ANOVA procedures and multiple, independent t-tests, and Tukey's HSD tests [15]. All tests were conducted at the $\alpha=.05$ level of significance, although exact levels of alpha are reported. A relatively small effect size was calculated using eta-squared $\left(\eta^{2}=.01\right)$.

\subsubsection{Results}

\section{Sample Selection}

Of an original 528 student email addresses that existed in this database, 78 were parceled out due to returned email addresses which were no longer viable (bouncebacks). After correcting the address or after alternate emails were obtained, 17 of the 78 invalid email addresses were successfully resent, leaving 467 remaining email responses from students. Of those, 145 surveys were unduplicated, useable surveys. Only complete, non-duplicated surveys were intended for use in this study. This resulted in a response rate of $31 \%$, reflecting an email return rate not uncommon in this type of study [16]. To protect the anonymity of the course management systems in this report, no identifying information is provided and will 
be reported as CMS A and CMS B. Participants were then grouped into three sub-sections accordance to experience with the CMS: 1) students who had only taken courses in CMS A, 2) students who had only taken courses in CMS B, and 3) students who had taken courses in both CMS A and CMS B.

\section{Demographics}

Participants $(\mathrm{N}=145)$ from a wide geographic area responded to the online survey, with $32 \%$ of respondents from the university's home state in the Mid-South. In all, 31 states were represented with seven responding from outside of the continental United States. Of the participants, 141 respondents reported age ranging from 20 to 66 , with a mean age of 39 . All respondents reported gender with $77 \%$ being female and $23 \%$ male. All except three respondents reported race, resulting in 24 African American, two American/Alaskan Indian, two Asian/Pacific Islander, 109 Caucasian, and 5 Hispanic participants. One hundred twenty-four chose to report disability status, with $73 \%$ reporting no disability and $27 \%$ reporting having had a disability. See Table 1.

Table 1. Demographic variables

\begin{tabular}{|c|c|c|}
\hline Variable & $\mathrm{N}$ & Percentage \\
\hline Female & 112 & $77.2 \%$ \\
\hline Male & 33 & $22.8 \%$ \\
\hline African American & 24 & $16.6 \%$ \\
\hline American Indian & 2 & $1.4 \%$ \\
\hline Asian & 2 & $1.4 \%$ \\
\hline Caucasian & 109 & $75.2 \%$ \\
\hline Hispanic & 5 & $3.4 \%$ \\
\hline Not reporting race & 3 & $2.1 \%$ \\
\hline Age 20-29 & 28 & $19.3 \%$ \\
\hline Age $30-39$ & 37 & $25.5 \%$ \\
\hline Age $40-49$ & 46 & $31.7 \%$ \\
\hline Age $50-59$ & 28 & $19.0 \%$ \\
\hline Age $>59$ & 2 & $1.4 \%$ \\
\hline Prefer Off-campus & 90 & $82.6 \%$ \\
\hline Prefer On-campus & 15 & $13.8 \%$ \\
\hline Disability & 34 & $23.4 \%$ \\
\hline No Disability & 90 & $62.1 \%$ \\
\hline Not reporting disability & 21 & $14.5 \%$ \\
\hline
\end{tabular}

* of those reporting

Participants' level of computer comfort was measured using a Likert-type scale ranging from 1 to 5 . About $40 \%$ of all participants agreed with having a comfort level in working with computers, while $50 \%$ strongly agreed, resulting in $90 \%$ of the respondents being relatively comfortable with computers. Just fewer than $8 \%$ were not sure and slightly over $2 \%$ felt not at all comfortable with computers in general. Participants in the survey were further asked whether or not they would be interested in an online Ph.D. program following their completion of the masters program. Of those responding to this question $(\mathrm{N}=77)$, $55.8 \%$ expressed interest in an online Ph.D. program, 32.5\% were undecided, and a mere $11.7 \%$ were not interested.

Research Question One

Were there significant differences among these student groups between preferences for the CMS A or B? To answer this question, a nonparametric Chi Square analysis was run to determine if expected values deviated significantly from observed. Results indicated no significant differences between the groups suggesting that little or no bias existed in favor of one course management platform over the other. See Table 2 .

Table 2. CMS A or CMS B

\begin{tabular}{|c|c|c|c|}
\hline & Observed N & Expected N & Residual \\
\hline CMS A & 74 & 70.0 & 4.0 \\
\hline CMS B & 66 & 70.0 & -4.0 \\
\hline Total & 140 & & \\
\hline & $\begin{array}{c}\text { CMS A or CMS } \\
\text { B }\end{array}$ & & \\
\hline $\begin{array}{c}\text { Chi-Square } \\
\text { (a) }\end{array}$ & .457 & & \\
\hline df & 1 & & \\
\hline $\begin{array}{c}\text { Asymp. } \\
\text { Sig. }\end{array}$ & .499 & & \\
\hline
\end{tabular}

Research Question Two

Were there significant differences among these student groups regarding their attitudes of their computer proficiency for CMS A or B? In answer to this question, respondents $(N$ $=109)$ were split almost evenly $(48.6 \%$ v. $47.7 \%$, respectively) resulting in no significant differences on this item. A one-way analysis of variance was used to further examine this data. Four groups existed as a result of the survey design: a) participants with no previous experience in either CMS B or CMS A $(n=51), \mathrm{b})$ those with experience in CMS B $(n=29), \mathrm{c})$ those with experience in CMS A $(n=14)$, and, d) those who had experience with both courseware delivery systems $(n=50)$.

No differences were found between the groups with experience in either one course delivery system or the other, suggesting that a change in course delivery systems does not necessarily have a negative effect upon experienced student users. Worth noting, the design of the courses (the skin) used in the CMS A platform was intentionally similar in appearance to that used in the previous CMS B platform. However, a significant difference was found between the group with no previous experience and the group with experience with both CMS A and B $(F(3,140)=4.92$, p $<.01)$. See Table 3. 
Table 3 Results of ANOVA on CMS B and CMS A groups.

\begin{tabular}{|c|c|c|c|c|c|c|}
\hline & SS & df & Mean Square & $F$ & Sig. & Eta-squared \\
\hline Between Groups & 872.356 & 3 & 290.785 & 4.916 & .003 & .01 \\
\hline Within Groups & 8280.532 & 140 & 59.147 & & & \\
\hline Total & 9152.889 & 143 & & & & \\
\hline
\end{tabular}

Tukey HSD

\begin{tabular}{|c|c|c|c|}
\hline expgroup & $\mathrm{N}$ & Subset for alpha $=.05$ & \\
\hline & & 1 & \\
\hline no exp & 51 & 54.35 & 57.14 \\
\hline exp in CMS B & 29 & 57.14 & 57.71 \\
\hline exp in CMS A & 14 & 57.71 & 60.22 \\
\hline exp in both & 50 & & .449 \\
\hline Sig. & & .371 & \\
\hline
\end{tabular}

Table 4 Correlations among variables including Computer Comfort, Previous Experience in Distance Education, Self-perceived learning and Hours Completed in the Program.

\begin{tabular}{|c|c|c|c|c|c|}
\hline & & $\begin{array}{c}\text { Computer } \\
\text { Comfort }\end{array}$ & $\begin{array}{c}\text { Previous DE } \\
\text { Experience }\end{array}$ & $\begin{array}{c}\text { Learn More } \\
\text { with DE }\end{array}$ & $\begin{array}{c}\text { Hours } \\
\text { Complete }\end{array}$ \\
\hline Computer Comfort & Pearson Correlation & 1 & $.238(* *)$ & $.389\left(^{* *}\right)$ & $.165\left(^{*}\right)$ \\
\hline & Sig. (2-tailed) & & .004 & .000 & .049 \\
\hline Previous DE Experience & Pearson Correlation & $.238(* *)$ & 1 & 144 & 144 \\
\hline & Sig. (2-tailed) & .004 & & .147 & $.229(* *)$ \\
\hline & N & 144 & 144 & .079 & .006 \\
\hline Learn More with DE & Pearson Correlation & $.389(* *)$ & .147 & 1 & 144 \\
\hline & Sig. (2-tailed) & .000 & .079 & 144 & $.228\left(^{* *}\right)$ \\
\hline & N & 144 & 144 & 144 & 144 \\
\hline Hours Complete & Pearson Correlation & $.165(*)$ & $.229(* *)$ & $.228(* *)$ & 1 \\
\hline & Sig. (2-tailed) & .049 & .006 & .006 & 144 \\
\hline
\end{tabular}

** Correlation is significant at the 0.01 level (2-tailed).

* Correlation is significant at the 0.05 level (2-tailed).

\section{Research Question Three}

Were there significant measurable correlations found among these student groups between specific demographic characteristics and their computer proficiency for the CMS B and CMS A? To answer this question, a Pearson Product Moment Correlation was applied to continuous variables thought to be involved in this question. A marginal but not significant relationship was noted between Computer Comfort and having previous experience with distance education $(r=.23, \mathrm{p}<.01)$. A similar relationship was noted between having had previous DE experience and hours in the $\operatorname{program}(r=.23, \mathrm{p}<.01)$. A relatively strong correlation was found between Computer Comfort and the perception of learning more through distance education when compared to conventional learning methods $(r=.39, \mathrm{p}<.001)$. This seems to support the notion that comfort with the use of computer systems in an online education environment may be concomitant with the perception that distance education can result in learning. See Table 4.Research Question Four

Were there significant differences among these student groups regarding instructional delivery methods and their course delivery preferences? In summary, when asked about preference for on-campus or distance education courses, $83.4 \%$ preferred distance education. If given a choice 
between chat rooms or discussion boards for distance classroom communication, $82 \%$ favored discussion boards over chat rooms. Participants were then asked to discriminate between methods of distance education delivery. Between asynchronous versus synchronous delivery of distance education courses, $88 \%$ preferred asynchronous over synchronous, with under $10 \%$ favoring synchronous and about $2 \%$ abstaining from this response item. In relation to text-based online courses versus videostreamed technology, this finding suggested that $86 \%$ of those responding $(n=109)$ favored a video streamed format over text-based material alone.

\section{Conclusion}

\subsection{Discussion}

The purpose of this study was to examine the perceptions and attitudes of students enrolled in DE while going through a change in platform compared to previous experience with the platforms. These results offer insight for future administrators as they plan for similar platform changes and the future of online learning environments as a whole.

The philosophy of the college program under study was consistent with previous research, indicating that the same content and skills training that occurs in an on-campus class can also be provided using an on-line format [12]. This philosophy is supported by the diverse instructional delivery methods described throughout. With this approach, the online content and experience may be compared favorably to what a student would encounter in attending an on-campus class.

Given that course familiarity was a key factor influencing student satisfaction with DE [9], a standard course template was encouraged for use by faculty, although this was not a requirement. Faculty who developed the web courses welcomed the universality, as did the students. Students often noted the benefit of familiarity from course to course since most course menu items and organization (i.e., location of syllabus, course modules, etc.) appeared similar from class to class regardless of the CMS being used. Matching the appearance of the course so that menu item choices appear in the same general locations on the pages may ease the confusion surrounding crossing platforms and eliminate some of complaints regarding ease of use mentioned in previous research.

\subsection{Discussion of Survey Results}

Concern over preference for a particular learning platform (i.e., CMS B versus CMS A), based upon this study, appears to be less salient to learners than expected. Perhaps the physical page appearance is more important since the learner's perspective may be more focused upon the use of the content rather than the type of CMS. Is this a question of form or function? As Marshall McLuhan[17] once wrote,
"The Medium is the Massage." Although participants in this study excluded faculty, teaching assistants and staff, the same may hold true for them. As often as staff and faculty switch from course to course, the implications of this study may suggest that having a relatively standard template may help prevent confusion and ease transition not only from one course management platform to another, but from course to course.

Once taken, the online course format appears to appeal to learners. The vast majority of those participating in this study preferred a distanced learning format to a conventional classroom learning environment. The results of this study indicated that a majority $(60 \%)$ of respondents would be interested in a Ph.D. program. Given the growth of distance education, this may support administrators interested in developing higher level degree programs online.

A secondary finding from this study occurred after analyzing the data. Part of the methodology included the email/survey package, which was designed, built, tested and made available to email recipients for the specific purpose of this study. Since participants in this study were already familiar (to one extent or another) with online learning and were accustomed to checking email regularly, it seemed natural to use an email prompting system with an embedded link that took the willing participant directly to the initial survey page. Did this ease of process help to increase participation?

Among the more interesting results of this survey were the findings in regards to instructional methods utilized. Discussion boards $(82 \%)$ were favored over chat rooms, asynchronous $(88 \%)$ delivery methods were preferred over synchronous delivery of course material, and videostreamed $(86 \%)$ format was preferred over text-based material alone.

In light of these findings, additional research may focus on the interference of technical difficulties on such objective evaluation of student progress. Such research could evaluate the importance of independence in the assessment of student outcomes, such that there is not a confounding effect created, given the heterogeneity of variance of technical expertise that may exist in the group being evaluated. More to the point, the effect of that lack of technical ability may interfere with student performance, and thus be reflected in the assessment and take the focus off learning and onto the technology itself. Such errors of independence could be initiated by a slow responding website, error in transmission over the Internet that could result in information not making it to the course platform even though the sender perceived it as being sent, or any other such confounding issue that interferes with learning, driving the problem to one of technology, not of education.

\subsection{Limitations}

One of the confounding effects of the comparison between CMS A and CMS B involved the appearance of courses in either platform. Regardless of the course management system delivered, the program under study used a 
standardized format so that all courses looked familiar to students on the surface. In other words, the main menu items on the homepage of all courses looked similar, easing the process of locating course material such as the syllabi, course outline, assignments, etc., regardless of which CMS was used. This may have confounded the comparison, minimizing the differences within the course management systems.

Paradoxically, a second confounding effect may be related to the use of videostreamed lecture segments within the program's courses. Of course, as with any lecture, the quality of the instructor's delivery, whether in the classroom or recorded on a video, combined with curriculum, can have an effect, further confounding the results. Although students who participated in this survey found the videostreams to be superior to text-based learning alone, this may have added to the positive responses elicited in the survey from students regarding the efficacy of distance education. The opposite side of that effect may provide a guideline to those planning to convert to a new course delivery platform. A different perspective of the same issue may be posited. Today, with the surge of online educational videos available through web resources such as YouTube, for example, the trend toward video based learning over text alone is likely to continue.

A seemingly obvious consideration regarding overwhelming student preference for online learning may stem from the participants themselves, who were enrolled in a distance education program. If students were directly opposed to distance education, they would probably not have chosen to be in the program. However, the variable in question, the comparison of distance education versus conventional classroom preference was intended to gather data based upon the foregone conclusion that, until recently, learning was almost exclusively within brick and mortar classrooms. That paradigm may be changing rapidly as the move toward distance education continues to prevail. The presumption that participants had sufficient grounds for personal preference comparison was given. This, however, does not exclude the possibility that participants who did not prefer distance education would remain in the program. In fact, several participants did suggest a preference for classroom learning, adding validity to the issue.

In relation to sampling bias, although a complete list of potential participants served as the mailing list, the sample design of this study was intentional. Since the participants in the study were solicited freely, those who were more comfortable with computers in general may have self-selected over those who were somewhat less comfortable. Although this did not appear to be of major concern, it must be addressed.

\subsection{Implications and Future Research}

In conclusion, distance education can be an acceptable learning environment as perceived by a significant margin of students who have had the opportunity to participate in both conventional classroom and distance education settings.
Online course format appears to appeal to learners. Worthy of note, participants in this study consisted of students exposed to online videostreamed classes specifically designed to appear similar in format and structure, although content varied from course to course.

Differences in course delivery platforms, at least in this study, did not appear to have a significant impact on student learners. Although the two course platforms may appear significantly different to course builders, faculty and support staff, if the skin (general appearance) of the course is as similar as platforms allow, then problems resulting from the differences in appearance to the students appears to be minimized. To generalize, transition from any one platform to another may not be as important to students as it might to course developers, faculty, or administration, particularly if the design of the online course appears similar to the student.

Future research might attempt to add more focus toward evidence-based teaching and learning. The program investigated in this study operates within a field governed by nationally standardized examinations. Results of those examinations may be included in future studies of this type to add a component related to outcomes. In addition, given the current economic climate for education and ecology, distance education can provide considerable benefit. Yet students continue to vary in their perceptions toward online education and in their experiences [18]. Cost-performance benefit of distance education and careful evaluation of outcome-based evidence could add to the research base. Additional research may focus on the interference of technical difficulties on such objective evaluation of student progress. Such research could evaluate the importance of independence in the assessment of student outcomes, such that there is no confound created given the variability of technical expertise that may exist in the group being evaluated. More to the point, the effect of that lack of technical ability may interfere with student performance, and thus be reflected in the assessment and take the focus off learning and onto the technology itself. Such errors of independence could be initiated by a slow responding website, error in transmission over the Internet, a computer virus at the user side, CMS bugs, firewalls, glitches or crashes, or any host of issues that may interfere with information not making it to or from the course management platform, even though the sender perceived it as being sent, or any other such confounding issue that interferes with learning, driving the problem to one of technology, not of education.

\section{REFERENCES}

[1] Allen, M., Mabry, E., Mattrey, M., Bourhis, J., Titsworth, S., \& Burrell. N. (2004). Evaluating the effectiveness of distance learning: A comparison using meta-analysis. Journal of Communication, 54(3), 402-420. 
[2] Maguire, M. (2005). Literature Review - Faculty participation in online distance education: Barriers and motivators. Online Journal of Distance Learning Administration, $\operatorname{VIII}(\mathrm{I}), 1-17$.

[3] Andrew, J. (2004). A comprehensive survey of the status of distance education in rehabilitation counselor education training at the Master's degree level. Final Report: Switzer Distinguished Fellowship. Award number: H133F020004.

[4] Forster, M., \& Washington, E. (2000). A model for developing and managing distance education programs using interactive video technology. Journal of Social Work Education, 36(1), 147-158.

[5] Lorenzetti, J. (2003). Thirty-two distance education trends. Distance education report, 7(21), 1-6.

[6] Lei, S.A., \& Gupta, R.K. (2010). College distance education courses: Evaluation benefits and costs from institutional, faculty and students' perspectives. Education, 130(4), 616-631.

[7] Rad. P. (2002). Distance education. Cost Engineering, 44(6), 9-12.

[8] McLean, M., \& Murrell, K. (2002). CMS A: Integrating computer-mediated communication and resource delivery into a new problem-based curriculum. Journal of Audiovisual Media in Medicine, 25(1), 8-15.

[9] Bequiri, M.S., Chase, N.M., \& Bishka, A. (2010). Online course delivery: An empirical investigation of factors affective student satisfaction. Journal of Education for Business, 85, 95-100. doi: 10.1080/08832320903258527.
[10] Falvo, D.A. \& Johnson, B.F. (2007). The use of learning management systems in the United States. TechTrends, 51(2), 40-45.

[11] Smart, K., \& Meyer, K. (2005). Changing course management systems: Lessons learned. Educause Quarterly, 28(2), 68-70.

[12] Ross, K. R., et al. (2002). Quality assurance for distance education: A faculty peer review process. TechTrends, 46(5), 43-52.

[13] Hunt, O. (2007). A mixed-method design. Retrieved March 24th, 2009 from http://www.articlealley.com/article_185975 22.html.

[14] Thorndike, R.M., Cunningham, G., Thorndike, R.L., \& Hagen, E. (1991). Measurement and evaluation in psychology and education (5th ed.). New York: Macmillan Publishing.

[15] Minium, E., King, B., \& Bear, G. (1993). Statistical reasoning in psychology and education (3rd ed.). New York: John Wiley \& Sons.

[16] Sheehan, K., \& Hoy, M. (1999). Using e-mail to survey Internet users in the United States: Methodology and assessment. The Journal of Computer-Mediated Communication, 4(1), 1-26.

[17] McLuhan, M., \& Fiore, Q. (1967). The medium is the massage. New York: Bantam Books.

[18] Muilenburg, L.Y., \& Berge, Z.L. (2005). Student barriers to online learning: A factor analytic study. Distance Education, 26(1), 29-48 